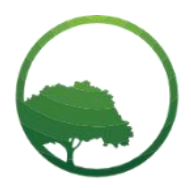

Research in Business \& Social Science

IJRBS VOL 10 NO 7 ISSN: 2147-4478

\title{
The conceptualization of dynamic resource orchestration framework as an anchor for organizational resilience
}

\author{
(D) Eltigani Ahmed ${ }^{(a) *(10)}$ James Kilika ${ }^{(b)}$ (D) Clare Gakenia ${ }^{(c)}$ \\ ${ }^{(a)}$ School of Leadership, Business and Technology, PAC University, Nairobi, Kenya \\ ${ }^{(b)}$ Department of Business Administration, Kenyatta University, Nairobi, Kenya. \\ ${ }^{(c)}$ Senior Lecturer, School of Leadership, Business and Technology, PAC University, Nairobi, Kenya
}

\author{
A R T ICLE INFO \\ Article history: \\ Received 16 September 2021 \\ Received in rev. form 21Oct. 2021 \\ Accepted 28 October 2021 \\ Keywords: \\ Dynamic Resource Orchestration \\ Framework, Dynamic Capabilities \\ Framework, Resource-Based View \\ Theory, Disruption, Organizational \\ Resilience. \\ JEL Classification: \\ D21, D23
}

\begin{abstract}
A B S T R A C T
The objective of this paper was to present dynamic resource orchestration framework as a source of organizational resilience through blended orchestration of the firm's dynamic and static resources to generate sustained value during disruptive shocks. We adopted an integrative literature review methodology and proposed dynamic resource orchestration framework as a managerial option to create and sustain firm value. Conceptually, dynamic resource orchestration framework was presented as the integration of firm resources and managerial capability. We proposed dynamic resource orchestration as a model input impacting organizational resilience through the combined effects of resource accumulation, resource orchestration, and managerial capabilities. Through a thorough examination of the literature production anchored on dynamic capabilities framework and organizational resilience, we advanced a perspective that the ultimate source of combined firm resilience and sustainable competitive advantage does not necessarily accrue from the resources at a firm's disposal but by how management dynamically blends and orchestrates the existing resources, thereby creating an optimal source of capability. Our proposed conceptualization was based on the assumption that dynamic capabilities are part of firm resources and, therefore, strategic orchestration of dynamic capabilities leads to superior firm resourcefulness and consequential sustained resilience. We identified gaps and proposed direction for future research.
\end{abstract}

(C) 2021 by the authors. Licensee SSBFNET, Istanbul, Turkey. This article is an open access article distributed under the terms and conditions of the Creative Commons Attribution (CC BY) license (http://creativecommons.org/licenses/by/4.0/).

\section{Introduction}

The resource-based view theory and dynamic capabilities framework have dominated strategic firm resource management thinking and practice for some time now (Banerjee et al., 2018; Collins, 2020; Takahashi et al., 2017). However, the increasingly volatile and uncertain environment has stretched their practical relevance and called for a new approach to understanding some contemporary cases of organizational failure despite resourcefulness (Petricevic \& Teece, 2019). This call has reverberated a parallel call to rethinking the fundamentals of leadership theory to reposition leadership within the strategic organizational circumferences (Anderson \& Sun, 2017; Dinh et al., 2014). The increased frequency and expanded magnitude of systemic crises in recent years provided mixed fortunes for firms operating within homogeneous environments. Evidence suggests that systemic crises or disruptive shocks create the potential for firms to exploit and grow with the timely and efficient deployment of dynamic resources (Bojesson \& Fundin, 2020). According to Binti Samsudin and Ismail (2019), dynamic recalibration of firm resources is a fundamental addition of the dynamic capability's framework to the original resource-based view theory proposition. One of the enduring dimensions of dynamic capabilities framework with ongoing relevance to date is reconfiguration capability characterized by the recombination and redeployment of resources (Zhou et al., 2019).

Nevertheless, recent disruptive shocks and systemic events have revealed that, to achieve targeted resilience, firms need to possess and orchestrate dynamic blending capabilities that entail a firm's intrinsic capacity to orchestrate resources more than the mere stock

* Corresponding author. ORCID ID: 0000-0001-6983-1580

(C) 2021 by the authors. Hosting by SSBFNET. Peer review under responsibility of Center for Strategic Studies in Business and Finance. https://doi.org/10.20525/ijrbs.v10i7.1419 
of resources at its disposal. According to Laaksonen and Peltoniemi (2018), a firm may invest in resources that prove to be irrelevant to its market environment during disruptive shocks. This is because mere possession of resources may not necessarily yield results. Instead, the resources are altered by the firm's inherent dynamic capabilities. This extension from resources to capabilities, which remains unaddressed in the dynamic capabilities' framework, has been underscored in emerging literature (Binti Samsudin \& Ismail, 2019). In the wake of these limitations, the dynamic resource orchestration framework could be proposed as an emerging direction in leadership strategy and firm sustainability literature, making orderly advancement in the burrows of resource-based view theory and dynamic capabilities framework.

Thus, a trend in pioneering firm resilience literature has taken shape in the form of dynamic resource orchestration framework as the most recent evolution of theoretical frameworks that inform the development and attainment of sustainable competitive advantage in a volatile environment (Ahuja \& Chan, 2017; Flammer \& Ioannou, 2018). dynamic resource orchestration framework originated from cloud computing and was first proposed by Professor John McCarthy in 1961 (Gillam \& Antonopoulos, 2017). The framework is based on the idea of outsourcing some back-end computing infrastructure components to reduce overheads costs per unit of computing and increase convenience and affordability for front-end users. Regarded from a firm resource angle, the idea of dynamic resource orchestration framework is anchored on the argument that sustainable competitive advantage accrues from the accumulation, leveraging, and bundling of organizational resources (Rehman et al., 2019). However, the concept's development is still in its nascent stages, opening the field for further exploration through ongoing scholarly discourse. Moreover, while this development is taking its course, several recent systemic disruptive shocks, including the 2008 global financial crisis and the continuing Covid-19 pandemic, have catapulted the salience of dynamic resource orchestration framework to center-stage and rekindled interest in the manner in which firms emerge from disruptive shocks (Hitt et al., 2020).

Against cataclysmic upheavals such as the Covid-19 pandemic and other comparable systemic disruptive shocks, this article proposes dynamic resource orchestration framework as an outgrowth of resource-based view theory and an advancement into dynamic capabilities framework discourse. By critically examining literature production anchored on dynamic capabilities framework and the emergent resource orchestration discourse, the article advances the perspective that while dynamic capabilities framework has earned its place in the strategic management literature, the ultimate source of combined firm resilience and sustainable competitive advantage during dynamic times does not necessarily accrue from strategic resources or dynamic capabilities possessed by a firm but by the way management and leadership actively blend and orchestrate the existing dynamic resources, thereby creating additional marginal capabilities from the resource blend and achieving sustained resilience. In straightforward terms, this paper presents the dynamic resource orchestration framework as a blend of resource-based view theory, dynamic capabilities framework, and organizational resilience where resource-based view refers to resource source and dynamic capabilities refer to the resource application, conjointly determining the optimal level of organizational resilience. The central argument is that dynamic resource blending creates multiple desirable resource equilibria at each given volume of resources for the firm. The article uses an integrative review methodology to argue that dynamic capabilities are a resource and that the strategic orchestration of dynamic capabilities leads to superior firm resourcefulness and consequential resilience. In the end, this article presents dynamic resource orchestration framework that can help steer firms through systemic environmental disruptions.

\section{Review of Theoretical Literature}

The term "dynamic capabilities" stems from a proposition that a firm possesses reconfigurable capabilities to respond to a demanding situation. According to Binti Samsudin and Ismail (2019), dynamic capabilities represent a firm's ability to recalibrate its domestic and external resources to respond to ecosystem contingencies. A similar argument has been presented by Duchek (2020), who decomposed dynamic capabilities into three sub-dimensions, including anticipation capabilities, coping capabilities, and adaptation capabilities. He argued that anticipation capabilities entail risk forecasting to inform decisions that must be made now to circumvent future disruptions. This involves environmental scanning, identifying critical developments and possible threats, and developing response mechanisms to both expected and unexpected occurrences. Coping capabilities entail making sense of and swinging plans into action and developing and implementing ad-hoc solutions. Adaptation capabilities comprise firm advancement strategies, including transformation and learning required to respond more effectively to future crises. The growing interest in identifying and measuring organization resilience led to the documentation of several factors that assess resilience from various angles, including environmental, firm-specific, macroeconomic, technical, and sociocultural arenas.

Dynamic capability is closed related to firm resilience. According to Menéndez Blanco (2018), firm resilience entails the firm's ability to identify growth prospects and market challenges, invest in positive opportunities and manage threats, maintain, reshape, and reconfigure existing inherent capabilities. This argument finds support from extant empirical literature, which demonstrates the continued utility of dynamic capabilities framework in a volatile environment (Ochieng, 2018). For instance, Navarro García et al. (2018) examined dynamic capabilities and performance in the European motor industry. Their results showed that dynamic capabilities enabled firms to adapt to constant changes and compete in turbulent environments. However, a study by Collis and Anand (2018) in the United States' corporate sector found that dynamic capabilities can lead to a sustainable competitive advantage but only when the resources are valuable, rare, inimitable, and non-substitutable. This affirms the findings of Navarro García et al. (2018) that the conditions under which dynamic resource orchestration framework contributes to competitive advantage, suggesting that not all resources have strategic value. This invites the need to put the meaning and conceptualization of resources into perspective. 
Different scholars approach resource definition differently, but they all converge toward the idea that resources are assets or inputs deployed by a firm to ensure survival and continuity (Arrighetti et al., 2018; Chukwuemeka \& Onuoha, 2018; Gao et al., 2017). Many scholars distinguish between tangible and intangible resources (Akaeze, 2016; Gupta, 2019; Masood et al., 2019). The broad range of inputs characterizing the definition of resources encompass not just the human and material resources but also include partnerships (Ahuja \& Chan, 2017), corporate reputation (Almeida \& Coelho, 2017), and capabilities (Su \& Linderman, 2016).

Within firm resilience literature, there is growing attention to the concept of slack resources, which are the bundle of assets a firm has more than that which is required to sustain day to day operations (Gao et al., 2017; Karacay, 2017; Kiss et al., 2018; Navarro García et al., 2018; Vanacker et al., 2017). Some scholars have given such slack resources salience as they are seen to cushion firms against environmental shocks (Karacay, 2017; Omar et al., 2020). In this respect, Vanacker et al. (2017) delineate three subdimensions of slack resources: available slack, recoverable slack, and potential slack. They defined available slack as the excess liquidity or capital reserves that a firm can use to absorb shocks. They equate recoverable slack with inventories and accounts receivables that a firm can quickly convert into cash and use to sustain itself in times of distress. Potential slack is the accessible but unused credit lines that a firm can tap into when the need arises to smoothen income fluctuations or disruptions (Nguyen et al., 2019). Such slack is argued to be essential for firm sustainability because they afford the firm the flexibility needed to rapidly respond to environmental disruptions, although some believe that slack resources make firms inefficient (Bao et al., 2020; Sun et al., 2020). In contrast, no empirical evidence has been presented to support the argument that slack resources make firms less efficient (Vanacker et al., 2017).

Slack resources result from firms' strategies to survive environmental shocks and thrive by taking advantage of emerging opportunities (Nguyen et al., 2019). This has led to the concept of resource orchestration, which focuses on the deployment of firm resources effectively by structuring the portfolio of human and material resources at their disposal, bundling the resources into capabilities, and leveraging those capabilities to create value (Berseck, 2018). This implies that dynamic resource orchestration framework potentially explains why some firms are more resilient to ecological shocks (Furnival et al., 2019). Thus, dynamic resource orchestration framework has been proffered in the era of disruption as an amalgam of operational, tactical, and strategic actions that select, configure, combine, deploy, and manage assets and resources and describe the firm capacity to create, modify or extend resources through processes of structuring, bundling and leveraging of resources into capabilities (Kuratko \& Hoskinson, 2018). It describes the technical process of selecting and structuring human and material resources, including social networks and technological and financial assets, to exploit opportunities and create value (Welter et al., 2012).

According to Ahuja and Chan (2017), dynamic resource orchestration framework is broadly defined as a firm's drive toward value maximization through creating new product and service capabilities by reconfiguring and combining existing resources and capabilities, thus building new, more valuable capabilities in dynamic and uncertain business environment. Through resource orchestration, an analysis of how selection and structuring of human, social, financial, and technological resources can be used to exploit opportunities and gain competitive advantage, achieve growth, and create value (Ahuja \& Chan, 2017).

Structuring a resource portfolio involves resource acquisition and build-up through internal development and divestment (Berseck, 2018; Hitt et al., 2020). It is a process that involves identification and investment in high-value resources, conversion of high-value resources into capabilities, and undertaking additional investment to convert the capabilities into sustained value. Acquiring refers to firm's endeavor to attract or obtain resources from non-homogeneous markets (Boss, 2014). The resources that can be acquired form non-homogenous markets include knowledge, slack finance, tangible and intangible assets (Hitt et al., 2020). Finally, accumulating denotes firm ability to build up resources either within homogenous environment or developing resources from internal investment in material and human resources, including investment in human capital and accumulation of knowledge capabilities (Boss, 2014).

Drawing from the three dimensions, Rouwmaat (2012) developed a framework for measuring resource orchestration, wherein structuring was indicated by five sub-dimensions: acquisition, accumulation, divestment, governance and organizational structure, and business model. Koentjoro and Eliyana (2015) expanded the number of dimensions in their conceptualization of dynamic resource orchestration framework and added asset search and selection, configuration and deployment, and innovation and proactivity.

\section{Conceptual and Empirical Literature}

Omar et al. (2020) also studied the impact of the Covid-19 lockdown on the survival strategies of firms in Malaysia. They established that pre-crisis resilience strategies prepared the firms for Covid disruptions through asset acquisition and working capital rationing. The study also demonstrated that firms reconfigured their cash flows. The study showed that resource flexibility was associated with organizational resilience. Furthermore, resource slack cushioned firms from Covid lockdown shocks.

Sutanto and Sudarsono (2018) empirically analyzed 43 listed Indonesian banks and found that capital adequacy ratio, branch network, and brand value are significantly related to bank competitiveness, measured by return on asset and equity. The results suggested that slack resources, physical resources, and intangible resources influenced firm sustainability. These studies, while not exhaustive, accord salience to select resources and underscore the implications of their orchestration.

Barasa et al. (2018) reviewed empirical literature from health and other sectors to find evidence of organizational resilience. They concluded that resilience is synonymous with a system's potential for achieving its stated goals in crises. The resilience concepts used 
in the selected papers emphasized the ability to endure the strain and adjust and transform. According to Barasa et al. (2018), factors that influence organizational resilience include tangible assets, proactivity, technology, corporate governance, leadership and management capabilities, organizational culture, human capital, social intelligence, and teamwork. The scholars delineate the factors that make the organizational environment conducive for resilience against shocks. An important concept they introduce is transformation, meaning that an organization can positively emerge from crises through its intrinsic transformative powers.

Ma et al. (2018) examined contemporary organizational resilience literature and proposed a model to assess the construct more inclusively. The Authors tracked the emergence and conceptualization of resilience and provided useful pointers to future research directions that edify foundations of continued scholarly works. Their work's key feature is developing an integrated model of organizational resilience that decomposes organizational resilience into three sub-types: behavioral resilience, cognitive resilience, and contextual resilience. However, they make several propositions that were not subjected to hypothesis testing. The Authors called for future research into, among others, the empirical validation of organizational resilience theory and the business implications of organizational resilience, implying the existence of a knowledge gap.

Koronis and Ponis (2018) argued that organizational resilience pillars require a resilience culture as a core anchor for sustained organizational resilience. The Authors consolidate insights from case studies and empirical research, culminating in identifying critical dimensions of organizational resilience. Unlike the dominant stream of literature on resilience, the Authors innovatively embed cultural characteristics in their proposed strategic framework for building a resilient organization. The Authors' use of case comparisons blends theory with reality on the ground and demonstrates the elements that characterize resilient organizations from the rest.

Vanacker et al. (2017) studied the nexus between slack resources, organizational success, and the institutional characteristics using longitudinal data from private corporate in several European countries. They found that financial slack enhances a firm's performance at a decreasing rate, while human resource slack lowers performance at a decreasing rate. The study has focused on dynamic resource orchestration framework by spotlighting slack resources and revealed that not all resources contribute positively to firm resilience.

Gao et al. (2017) established that reputation is a meta resource that provides firms with transactional confidence during crises and uncertainty. The study provides a useful conceptual lens for theorizing firm resources and their pathway to firm resilience. The study differentiates between conventional resources and meta resources and suggests that conventional resources are precursors of organizational meta resources.

Ruiz-Martin et al. (2017) proposed a viable systems model as a framework for designing resilient organizations. Their literature review indicated that it is difficult to reach a consensus among the factors that enhance organizational resilience and measure it. They illustrate organizational resilience through the lenses of the Viable System Model. As a result, they distinguish between resilient and viable ones and suggest that organizations recover from disruptive events and thrive. Their work offers a simple framework for the identification of the shared characteristics between resilient and viable organizations.

\section{Methodology}

According to Jones-Devitt et al. (2017), the integrative review is characterized by utilizing varied data sources drawn from the theoretical and empirical literature. It combines data from a multiplicity of research designs and disregards the notion of their mutual exclusivity. This insight has been echoed by Snyder (2019), who posits that an integrative review approach is applied when there is a need to combine disparate perspectives and insights from different fields to develop novel theoretical models. Hence, it takes a broader look at the phenomenon under scrutiny. Therefore, this approach has been considered appropriate to guide the critical review and reconceptualization and expansion of extant theories of concern as they develop, particularly taking into account the apparent heterogeneity among resource management discourses and the attempt in this study to infuse elements from leadership strategy, organizational resilience, and systemic crisis. Therefore, one would argue that an integrative approach will be handy in blending these disparate discourses into coherent novel propositions.

This paper adopts the integrative review framework proposed and refined by Toronto and Remington (2020), which provides a stepby-step guide for conducting an integrative review. In this respect, a synthesis of the theoretical and empirical literature is undertaken to address the present state of extant evidence, prevailing gaps, and future research directions. The review exercise involves screening the abstracts, selecting the relevant articles, and then reading the full text to make a final selection. Data was abstracted based on descriptive information such as year of publication, topic, and type of study (Snyder, 2019). Furthermore, in keeping with (JonesDevitt et al., 2017), specific search terms were included in the query, such as "resource-based view," "dynamic capabilities view," "resource orchestration view," "dynamic resources," and "organizational resilience." The search was conducted using Crossref, Google Scholar, and PubMed, besides Advanced Google Search for open access literature, including unpublished postgraduate researches from institutional databases. An elimination criterion was set to ensure the extraction of the relevant material. In this respect, the paper included in the preliminary screening only the articles that contain the exact keywords in either the title or the abstract, with non-qualifying publications eliminated at the initial screening stage. For additional relevance, temporal criteria were added to eliminate publications older than ten years. The literature was then appraised for methodological soundness while constant comparison was performed in parallel to extract themes that form the basis of analysis, literature synthesis, discussions, and conclusions. The review was conducted following the six steps of the integrative review process, as shown in Figure 1. 


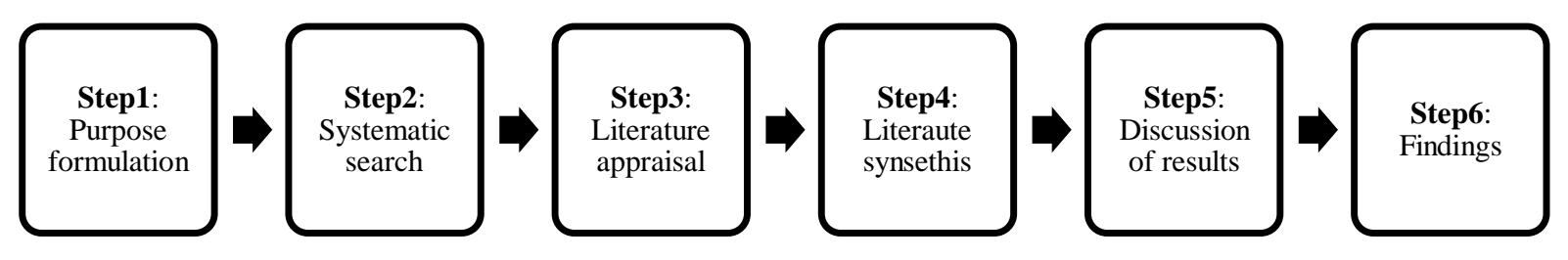

Figure 1: Stepwise Integrative Review Process

\section{Conceptual Framework}

The paper distinguishes between dynamic and static resources by defining dynamic resources as those strategic classes of resources that an organization either possesses or has at its disposal that it can reconfigure and redeploy at short notice to respond to disruptive events. Dynamic resources enable firms to adjust resource blends, thereby maintaining the firm's competitiveness (Murschetz et al., 2020). This is contrasted to static resources, a term used in this paper to refer to all the other resources possessed by an organization that may be difficult to reconfigure and redeploy at will or without a heavy cost. Unlike static resources, dynamic resources foster the organizational agility required to navigate in a turbulent environment. Dynamic resources are readily available, movable, and disposable. They are quickly convertible, transferable, flexible, and customizable.

The paper identifies dynamic resources in two ways: by characteristic and by origin. In terms of characteristics, it classifies dynamic resources into two broad categories, namely: financial and nonfinancial. Dynamic financial resources refer to strategic financial slack that an organization has accumulated and kept on standby for use in environmental disruptions. These are divided into two subclassifications. The first sub-classification is internal financial slack - that is, all monetary assets that the organization owns. Liquidity is also gauged by the organization's inventory, accounts receivables, and prepaid costs.

The second sub-classification is external financial slack which is of three types. Type 1 refers to money or monetary equivalents readily accessible to the organization at relatively minimal if not zero cost. These include credit lines and trade credit. These are graded as Class B types of assets representing the next in line in terms of availability depending on the organization's creditworthiness. Type 2 depends on whether the organization offers essential products/services or not. Type 3 accrue from the goodwill that the organization possesses within its market.

The dynamic nonfinancial resources are typified as classes of resources that, while they cannot be readily convertible into cash, have monetary value and can be readily accessed and deployed by the organization at short notice. These resources include talent stock that the organization has accumulated over time. As is the case with Type 3 external financial slack, this category of dynamic resources also accrues from the organization's goodwill within its market. These resources are based on the social capital that the organization has accumulated over time. Organizations have ready access to such resources because of the excellent image that they have built in their community. These are graded as Class $\mathrm{C}$ types of dynamic resources.

Accordingly, this paper proposes that organizational resilience and competitiveness accrue from the strategic orchestration of the identified dynamic resources. The paper argues that organizations that orchestrate dynamic resources set themselves up with the agility needed to survive and thrive during disruptions. The paper does not claim to be the originator of dynamic resource orchestration framework but highlights and demonstrates that dynamic resource orchestration framework is an idea whose time has come (Fichera et al., 2020). Nevertheless, it is worth mentioning that Fichera et al.'s (2020) conceptualization of dynamic resource orchestration framework makes a limited contribution to strategic management theory due to their operationalization within the context of computer networking. This paper presents a broad concept of dynamic resource orchestration framework and reconfigures it to respond to broader and more realistic business demands of firms operating in volatile markets. 


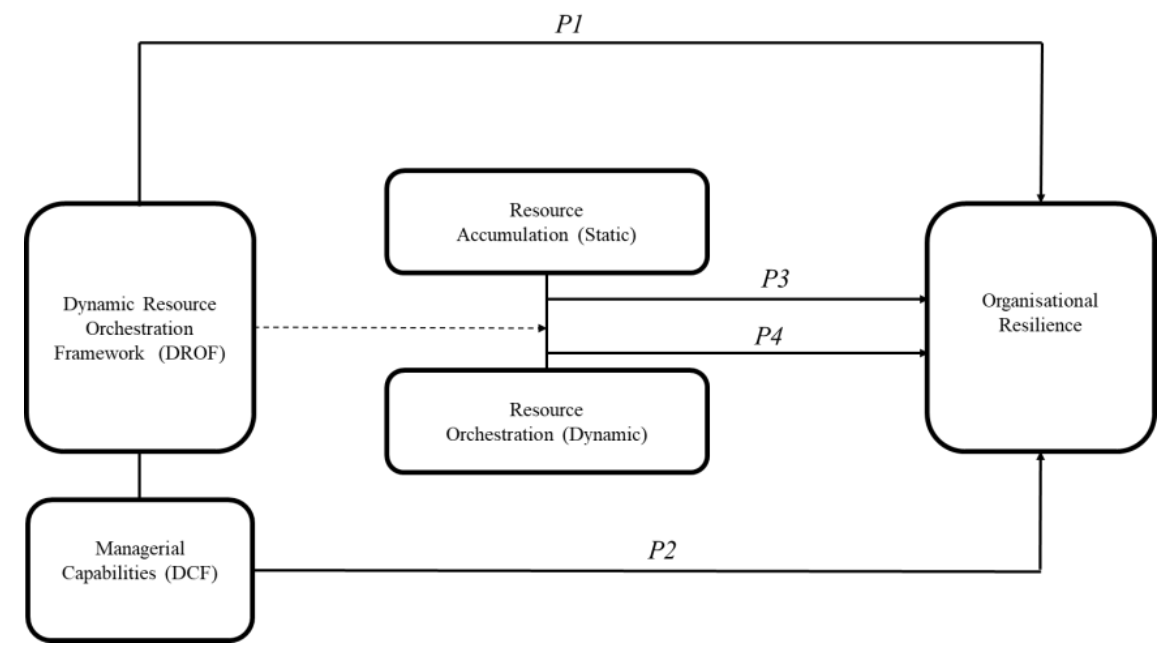

Figure 2: The dynamic resource orchestration framework

The framework proposed captures dynamic resource input factors of production as antecedents. Dynamic resource orchestration framework then intervenes both at the input stage to set up organizational processes for agility and at the output stage to gain further leverage from resource blends. The central argument is that resource blending creates multiple desirable resource equilibria at each given volume of resources for the firm. The proposed dynamic resource orchestration framework and its attendant framework conceptualize interaction with the extant literature and reflections on volatile operating environment.

\section{Theoretical Propositions}

The paper advances the following theoretical propositions:

i. There is no significant effect of firm dynamic resource orchestration on organizational resilience

ii. There is no significant mediating effect of firm resource stock on the relationship between firm dynamic resource orchestration and organizational resilience

iii. There is no significant mediating effect of firm resource orchestration on the relationship between firm dynamic resource orchestration and organizational resilience

iv. There is no significant moderating effect of managerial capabilities on the relationship between firm dynamic resource orchestration and organizational resilience

\section{Conclusions}

The dynamic resource orchestration framework has been proposed as an emerging thought in the burrows of resource-based view theory and dynamic capabilities framework. Building upon this new direction, the article pointed to dynamic resource orchestration framework as the most recent evolution of theoretical frameworks that inform the development and attainment of sustainable competitive advantage in a volatile world. The main contribution of this work to the strategic management theory is through reexamining the literature on dynamic capabilities framework and the emergent dynamic resource orchestration framework discourse. By advancing the idea that combined firm resilience and sustainable competitive advantage are the product of active blending and orchestration of the existing resources, a policy option has been proposed for firms to apply dynamic resource orchestration framework to create additional marginal capabilities from the resource blend to navigate through environmental disruptions.

However, it is critical to point out several gaps arising from this analysis. First and foremost, the theoretical proposition embedded in this paper remains to be tested on active data. Second, as it stands out now, there is still unsettled debate on the variable measures, exclusion lists, and interactions of the indicators relative to dynamic resource orchestration. Third, both resource-based view and dynamic capabilities propositions have been subjected to empirical data as evidenced by the number of studies in recent years; this is, however, not the case for dynamic resource orchestration. Perhaps, one of the feasible options is to assess model consistency on comparable firm resource data.

Finally, full development of the proposed conceptual model requires contribution, particularly in identifying and assessing variables and indicators, measurement techniques, and outcomes. Conceptualization alone represents only a tiny part of the model. Luckily, these gaps mean an opportunity for intellectual production in this area.

\section{References}

Ahuja, S., \& Chan, Y. E. (2017). Resource orchestration for IT-enabled innovation. Kindai management review, 5(1), 78-96. 
Akaeze, C. (2016). Exploring strategies required for small business sustainability in competitive environments Walden University]. Al-Balushi, M. (2019). Organizational Resilience through Quality Management: A Study on the Impact of the Implementation of Quality Management Principles on Resourcefulness University of Edinburgh]. UK.

Almeida, M. d. G. C., \& Coelho, A. M. (2017). The impact of corporate reputation in a dairy company. Business and Economics Journal, 8(4), 1-11.

Anderson, M. H., \& Sun, P. Y. (2017). Reviewing leadership styles: Overlaps and the need for a new 'full-range'theory. International Journal of Management Reviews, 19(1), 76-96. https://doi.org/https://doi.org/10.1111/ijmr.12082.

Arrighetti, A., Landini, F., \& Bartoloni, E. (2018). Firm survival during economic downturns: is selection based on cleansing or skill accumulation?

Banerjee, C. S., Farooq, A., \& Upadhyaya, S. (2018). The Relationship between Dynamic Capabilities, Competitive Advantage \& Organizational Performance. International Journal of Interdisciplinary Research and Innovations, 6(3), 603-610.

Bao, G., Zhang, W., Xiao, Z., \& Hine, D. (2020). Slack resources and growth performance: The mediating roles of product and process innovation capabilities. Asian Journal of Technology Innovation, 28(1), 60-76. https://doi.org/https://doi.org/10.1080/19761597.2019.1700383.

Barasa, E., Mbau, R., \& Gilson, L. (2018). What is resilience, and how can it be nurtured? A systematic review of the empirical literature on organizational resilience. International journal of health policy and management, 7(6), 491. https://doi.org/https://doi.org/10.15171/ijhpm.2018.06.

Berseck, N. (2018). Resource Orchestration as Source of Competitive Advantage of Cities-Empirical Studies of Business Improvement Districts in New York City and the City of Hamburg. Technische Universitaet Berlin (Germany).

Binti Samsudin, Z., \& Ismail, M. (2019). The Concept of Theory of Dynamic Capabilities in Changing Environment. International Journal of Academic Research in Business and Social Sciences, 9(6). https://doi.org/https://doi.org/10.6007/ijarbss/v9$\mathrm{i} 6 / 6068$.

Bojesson, C., \& Fundin, A. (2020). Exploring microfoundations of dynamic capabilities-challenges, barriers and enablers of organizational change. Journal of Organizational Change Management. https://doi.org/https://doi.org/10.1108/jocm-022020-0060.

Boss, D. S. (2014). Capabilities, configurations, and leveraging strategies: An investigation of the leveraging process of resource orchestration.

Chukwuemeka, O. W., \& Onuoha, B. (2018). Dynamic capabilities and competitive advantage of fast foods restaurants. International Journal of Management Science and Business Administration, 4(3), 7-14. https://doi.org/https://doi.org/10.18775/ijmsba.1849-5664-5419.2014.43.1001.

Collins, C. J. (2020). Expanding the resource based view model of strategic human resource management. The International Journal of Human Resource Management, 1-28. https://doi.org/https://doi.org/10.1080/09585192.2019.1711442.

Collis, D. J., \& Anand, B. N. (2018). The Limitations of Dynamic Capabilities. Harvard Business School Strategy Unit Working Paper(20-029). https://doi.org/https://doi.org/10.1561/111.00000017.

Didier, T., Huneeus, F., Larrain, M., \& Schmukler, S. L. (2021). Financing firms in hibernation during the COVID-19 pandemic. Journal of Financial Stability, 53, 100837. https://doi.org/https://doi.org/10.1596/33611.

Dinh, J. E., Lord, R. G., Gardner, W. L., Meuser, J. D., Liden, R. C., \& Hu, J. (2014). Leadership theory and research in the new millennium: Current theoretical trends and changing perspectives. The Leadership Quarterly, 25(1), 36-62. https://doi.org/https://doi.org/10.1016/j.leaqua.2013.11.005.

Drehmann, M., Farag, M., Tarashev, N., \& Tsatsaronis, K. (2020). Buffering Covid-19 losses-the role of prudential policy.

Duchek, S. (2020). Organizational resilience: a capability-based conceptualization. Business Research, 13(1), $215-246$. https://doi.org/https://doi.org/10.1007/s40685-019-0085-7.

Fichera, S., Martini, B., Martínez, R., Gharbaoui, M., Casellas, R., Vilalta, R., Muñoz, R., \& Castoldi, P. (2020). Experimental evaluation of dynamic resource orchestration in multi-layer (packet over flexi-grid optical) networks. Photonic Network Communications, 40(3), 137-148. https://doi.org/https://doi.org/10.1007/s11107-020-00899-4.

Flammer, C., \& Ioannou, I. (2018). To save or to invest? Strategic management during the financial crisis. Resource Based Strategy \& Policy.

Furnival, J., Boaden, R., \& Walshe, K. (2019). A dynamic capabilities view of improvement capability. Journal of Health Organization and Management. https://doi.org/https://doi.org/10.1108/jhom-11-2018-0342.

Gao, C., Zuzul, T., Jones, G., \& Khanna, T. (2017). Overcoming institutional voids: A reputation-based view of long-run survival. Strategic Management Journal, 38(11), 2147-2167. https://doi.org/https://doi.org/10.2139/ssrn.2894558.

Gillam, L., \& Antonopoulos, N. (2017). Cloud computing: principles, systems and applications. Springer.

Gupta, R. (2019). Entrepreneurship orientation (EO), resources, and small firm growth: Evidence from India. International Journal of Business and Economics, 18(1), 41-58.

Hitt, M. A., Arregle, J. L., \& Holmes, R. M. (2020). Strategic management theory in a post-pandemic and non-ergodic world. Journal of management studies. https://doi.org/https://doi.org/10.1111/joms.

Jones-Devitt, S., Austen, L., \& Parkin, H. (2017). Integrative Reviewing for exploring complex phenomena. Social Research Update(66). 
Karacay, M. (2017). Slack-performance relationship before, during and after a financial crisis: empirical evidence from European manufacturing firms the University of Birmingham].

Kiss, K. M., Lörincz, L., Csáfordi, Z., \& Lengyel, B. (2018). Related and unrelated diversification in crisis and in prosperity.

Koentjoro, S., \& Eliyana, A. (2015). Resource orchestration: Consolidation, integration, entrepreneurial and affective commitment in creating sustainable competitive advantage in the family firm. International Journal of Business and Social Science, 6(3).

Koronis, E., \& Ponis, S. (2018). Better than before: the resilient organization in crisis mode. Journal of Business Strategy. https://doi.org/ https://doi.org/10.1108/jbs-10-2016-0124

Kuratko, D. F., \& Hoskinson, S. (2018). The challenges of corporate entrepreneurship in the disruptive age. Emerald Group Publishing. https://doi.org/https://doi.org/10.1108/s1048-473620180000028011.

Laaksonen, O., \& Peltoniemi, M. (2018). The essence of dynamic capabilities and their measurement. International Journal of Management Reviews, 20(2), 184-205. https://doi.org/https://doi.org/10.1111/ijmr.12122.

Ma, Z., Xiao, L., \& Yin, J. (2018). Toward a dynamic model of organizational resilience. Nankai Business Review International. https://doi.org/https://doi.org/10.1108/nbri-07-2017-0041.

Masood, O., Aktan, B., Turen, S., Javaria, K., \& Abou ElSeoud, M. S. (2019). Which resources matter the most to firm performance? An experimental study. Management, 15(2), 74-80.

Menéndez Blanco, J. M. (2018). Organizational Resilience. How Learning Sustains Organizations in Crisis, Disaster, and Breakdown by D. Christopher KayesNew York, Oxford University Press, 2015192 pp. ISBN 978-0-19-979105-7 eISBN 978-0-19024584-9. The Learning Organization, 25(2), 143-146. https://doi.org/10.1108/tlo-07-2017-0074.

Morales Allende, M., Ruiz-Martin, C., Lopez-Paredes, A., \& Perez Ríos, J. M. (2017). Aligning organizational pathologies and organizational resilience indicators. International Journal of Production Management and Engineering, 5(2), 107-116. https://doi.org/https://doi.org/10.4995/ijpme.2017.7423.

Murschetz, P. C., Omidi, A., Oliver, J. J., Saraji, M. K., \& Javed, S. (2020). Dynamic capabilities in media management research. A literature review. Journal of Strategy and Management.

Navarro García, A., Rey Moreno, M., de Lima, P., \& Bártolo, P. D. A. (2018). Competitive advantages as a complete mediator variable in strategic resources, dynamic capabilities and performance relations in the car sales sector.

Nguyen, P. V., Huynh, H. T. N., Trieu, H. D. X., \& Tran, K. T. (2019). Internationalization, strategic slack resources, and firm performance: The case study of Vietnamese enterprises. Journal of Risk and Financial Management, 12(3), 144. https://doi.org/https://doi.org/10.3390/jrfm12030144.

Ochieng, A. O. (2018). Supply Chain Resilience and Organizational Performance of Pharmaceutical Manufacturing Companies in Nairobi university of nairobi].

Omar, A. R. C., Ishak, S., \& Jusoh, M. A. (2020). The impact of Covid-19 Movement Control Order on SMEs' businesses and survival strategies. Geografia-Malaysian Journal of Society and Space, 16(2). https://doi.org/https://doi.org/10.17576/geo2020-1602-11.

Petricevic, O., \& Teece, D. J. (2019). The structural reshaping of globalization: Implications for strategic sectors, profiting from innovation, and the multinational enterprise. Journal of International Business Studies, 50(9), 1487-1512. https://doi.org/https://doi.org/10.1057/s41267-019-00269-x.

Prayag, G., Chowdhury, M., Spector, S., \& Orchiston, C. (2018). Organizational resilience and financial performance. Annals of Tourism Research, 73(C), 193-196. https://doi.org/https://doi.org/10.1016/j.annals.2018.06.006.

Pulungan, S., Daihani, D. U., \& Arafah, W. (2018). The Influence Of firm Strategy and Organizational Resilience To Technology Orientation And it's implication To Company Performance of Coal Mining Company In Indonesia. International Journal of Business and Management Invention (IJBMI), 7(11), 62-73. www.ijbmi.org.

Rehman, S.-u., Mohamed, R., \& Ayoup, H. (2019). The mediating role of organizational capabilities between organizational performance and its determinants. Journal of Global Entrepreneurship Research, 9(1), 1-23. https://doi.org/https://doi.org/10.1186/s40497-019-0155-5.

Rouwmaat, E. (2012). Innovation and Imitation Barriers: the relationship between resource orchestration, imitation barriers for different process innovation contexts University of Twente].

Ruiz-Martin, C., Pérez Rios, J. M., Wainer, G., Pajares, J., Hernández, C., \& López-Paredes, A. (2017). The Application of the Viable System Model to Enhance Organizational Resilience. In Advances in Management Engineering (pp. 95-107). https://doi.org/10.1007/978-3-319-55889-9_5.

Snyder, H. (2019). Literature review as a research methodology: An overview and guidelines. Journal of Business Research, 104, 333-339. https://doi.org/https://doi.org/10.1016/j.jbusres.2019.07.039.

Su, H. C., \& Linderman, K. (2016). An empirical investigation in sustaining high-quality performance. Decision Sciences, 47(5), 787-819. https://doi.org/https://doi.org/10.1111/deci.12210.

Sun, Y., Du, S., \& Ding, Y. (2020). The Relationship between Slack Resources, Resource Bricolage, and Entrepreneurial Opportunity Identification-Based on Resource Opportunity Perspective. Sustainability, 12(3), 1199. https://doi.org/ https://doi.org/10.3390/su12031199.

Sutanto, E. M., \& Sudarsono, D. (2018). Empirical analysis of firm resources in the banking industry in Indonesia: A resource-based view Petra Christian University]. 
Takahashi, A. R. W., Bulgacov, S., Bitencourt, C. C., \& Kaynak, H. (2017). Expanding the dynamic capabilities view: Special contributions. Revista de Administração de Empresas, 57(3), 209-214. https://doi.org/https://doi.org/10.1590/s0034759020170302.

Teixeira, J. E., Serra, F., Pinto, R., \& Salles, L. (2019). Resource orchestration in a context of organizational decline. Management Research: Journal of the Iberoamerican Academy of Management. https://doi.org/https://doi.org/10.1108/mrjiam-07-20180841.

Toronto, C. E., \& Remington, R. (2020). Discussion and Conclusion. In A Step-by-Step Guide to Conducting an Integrative Review (pp. 71-84). Springer. https://doi.org/https://doi.org/10.1007/978-3-030-37504-1_6.

Vanacker, T., Collewaert, V., \& Zahra, S. A. (2017). Slack resources, firm performance, and the institutional context: evidence from privately held European firms. Strategic Management Journal, 38(6), 1305-1326.

Welter, F., Smallbone, D., \& Van Gils, A. (2012). Entrepreneurial processes in a changing economy: Frontiers in European entrepreneurship research. Edward Elgar Publishing. https://doi.org/https://doi.org/10.4337/9781781004739.

Zhou, S. S., Zhou, A. J., Feng, J., \& Jiang, S. (2019). Dynamic capabilities and organizational performance: The mediating role of innovation. Journal of Management \& Organization, 25(5), 731-747. https://doi.org/https://doi.org/10.1017/jmo.2017.20.

Publisher's Note: SSBFNET stays neutral with regard to jurisdictional claims in published maps and institutional affiliations.

\section{(1) (1)}

(C) 2021 by the authors. Licensee SSBFNET, Istanbul, Turkey. This article is an open access article distributed under the terms and conditions of the Creative Commons Attribution (CC BY) license (http://creativecommons.org/licenses/by/4.0/).

International Journal of Research in Business and Social Science (2147-4478) by SSBFNET is licensed under a Creative Commons Attribution 4.0 International License. 